\title{
Review: Isomer Separation, Chiral Resolution, and Structure Elucidation Analyses Are the Future of Analytical Supercritical Fluid Chromatography- Mass Spectrometry
}

\author{
Ilia Brondz ${ }^{*}$, Anton Brondz ${ }^{2}$ \\ ${ }^{1}$ Norwegian Drug Control and Drug Discovery Institute (NDCDDI), Ski, Norway, \\ Email: *ilia.brondz@gmail.com \\ ${ }^{2}$ Department of Chemistry, Norwegian University of Science and Technology, Trondheim, Norway, \\ Email: brondz@stud.ntnu.no
}

Received 18 January 2014; revised 25 February 2014; accepted 22 March 2014

Copyright (C) 2014 by authors and Scientific Research Publishing Inc.

This work is licensed under the Creative Commons Attribution International License (CC BY). http://creativecommons.org/licenses/by/4.0/

(c) (i) Open Access

\begin{abstract}
In 1822, almost 200 years ago, Baron Charles Cagniard de Latour (1777-1859) discovered the critical phenomena or critical state [1] [2]. At that time, it was described as a curiosity. However, it is now used as an advanced extraction and analytical technology in industry and research. Extraction with supercritical fluids (SFs) was welcome from the very beginning. In the present paper, the application to chromatography of the critical phenomena of compressed gases or overheated liquids as supercritical fluids will be discussed. Supercritical Fluid Chromatography (SFC) received an uneasy welcome, mainly because of the lack of commercially available analytical instruments. Even today, only a small number of industrial companies are manufacturing SFC instrumentation. A very small spectrum of columns is manufactured specially for SFC. SFC is not accepted by Pharmacopeia committees for the analysis of drugs and medical forms to the same extent as Gas Chromatography, High-Performance Liquid Chromatography or even Thin Layer Chromatography. The present status and future perspectives for SFC will be discussed.
\end{abstract}

\section{Keywords}

Critical Phenomena; Critical Stat; Supercritical Fluids; Supercritical Fluid Chromatography; Supercritical Fluids Extraction; Supercritical Fluid Chromatography—Mass Spectrometry

\footnotetext{
${ }^{*}$ Corresponding author.

How to cite this paper: Brondz, I. and Brondz, A. (2014) Review: Isomer Separation, Chiral Resolution, and Structure Elucidation Analyses Are the Future of Analytical Supercritical Fluid Chromatography-Mass Spectrometry. International Journal of Analytical Mass Spectrometry and Chromatography, 2, 15-24. http://dx.doi.org/10.4236/ijamsc.2014.21002
} 


\section{Introduction}

Several very important discoveries are used in modern Supercritical Fluid Chromatography-Mass Spectrometry (SFC-MS); they will make this technique one of the most important in chemical explorations. The first was the discovery of the critical phenomena by Baron Charles Cagniard de Latour in 1822 [1] [2], and the second was the discovery of chromatography, first described by M. Tswett in 1903 in [3], although the correct date of the phenomenon described by Tswett is somewhat later. The correct description of the process by Tswett was givenin 1906 in [4]. However, observations of the phenomenon used as the basis of chromatography were described earlier than 1903 and before Tswett. In 1897 and 1900, D. T. Day in [5] [6] presented experiments that can be accepted as chromatography. At about the same time in 1903 as Tswett presented his results, the scientists Kutscher and Steudel published a report [7] in which they described liquid-liquid partitioning, or in modern terms, Ascending Droplet Countercurrent Chromatography (ADCCC). Publications connected to the phenomenon thus occurred before Tswett's explanation in 1906 of its basis. If the priority in description of the phenomenon should be judged, we should also take into account the publication by Schønbein F. Über in 1861 [8]. The oldest known written description of the practical use of ion exchange chromatography for bulk preparation of fresh water from saline water is given in the Bible [9] and was mentioned in [10] [11].

The third important discovery for SFC-MS was the discovery of the Mass Spectrograph. The blueprint for the modern spectrometer was a Mass Spectrograph constructed in 1918-19 by Arthur J. Dempster and Francis W. Aston [12]. As for chromatography, the discovery and construction of MS were predicated on a long line of observations described by famous scientists starting from Julius Plücker in 1869, and Johann Wilhelm Hittorfand Eugen Goldstein, who in 1876 discovered and named the rays in gas discharges under low pressure as "Kanalstrahlen" or "canal rays" [13].

Neither chromatography nor mass spectrometry are chiral or enantioselective methods of analysis; however, by using chiral selectors in mobile phases or a chiral stationary phase in columns by chromatography it is possible to resolve enantiomers. SFC is an excellent methodology for separating all kinds of isomers, and by using chiral phases or chiral selectors it can be adapted to the resolution of enantiomers. Mass spectrometry is a highly selective method for recording differences in fragmentation of isomers; however, the MS alone is not enantioselective. The combination of these two methods gives a unique opportunity to study isomers of all types, including enantiomers.

Two different systems of SFC are provided by industry and have been used in laboratories. Both systems can be connected to the MS. One system is Capillary Column Supercritical Fluid Chromatography (CCSFC) and the other is Packed Column Supercritical Fluid Chromatography (PCSFC).

In 1958, J. Lovelock [14] discussed the idea of using Supercritical Fluids (SFs) as a mobile phase in chromatography. E. Klesper et al. in 1961 constructed the first working prototype of SFC [15]. Capillary Column Supercritical Fluid Chromatographs have much in common with Gas Chromatographs in construction, and in the early stages, existing Gas Chromatographs were redesigned for a new role. The PCSFC is an adaptation of HPLC to the demands of SFs. The instrumentation of Gas Chromatographs was adapted to SFs and similarly, high-pressure liquid chromatographs were adapted to SFs. $\mathrm{CO}_{2}, \mathrm{NH}_{3}, \mathrm{SF}_{6}$, and other compressible gases and low boiling-point liquids were used for experiments. These experiments were often unsuccessful because of attempts to translate the processes of GC or HPLC directly without adaptation to SFC and to use them to reconstruct the existing instrumentation of GC or HPLC. As a result of the high pressures required in SFCs, connections that were not adapted to these high pressures allowed continuous leakages of the mobile supercritical fluid phase, and the absence of backpressure regulators led to unstable conditions in columns; in addition, pumps froze.

\subsection{Capillary Column Supercritical Fluid Chromatography (CCSFC)}

As mentioned above, Capillary Column Supercritical Fluid Chromatographs were derived from Gas Chromatographs, so the use of capillary columns in CCSFC was predetermined. Because of this, many restrictions were inbuilt in construction, but the CCSFC also has many advantages.

The stability of phases in capillary columns in the new constructions was achieved by using an automatic capillary backpressure regulator made from noble metals, or a piece of thin capillary in the old constructions was used and connected after the column to stabilize the back pressure. The diameter and length of the capillary regulated the backpressure in the column. Some problems with chromatographic peak widening were observed in detectors. The precision of the determination of retention times was to some extent compromised in these old in- 
struments. The restrictions on construction of the tank that contained SFs required the use of a single-component mobile supercritical fluid phase without the possibility of controlling the composition of the mobile phase in CCSFCs. A single-component mobile phase could contain some additives such as a few percent of formic acid in $\mathrm{CO}_{2}$. However, it was impossible to achieve stable concentrations of additive in $\mathrm{CO}_{2}$ of mobile phase: the composition of mobile phase changed constantly during the emptying of the tank. Thus, the best results were achieved with pure $\mathrm{CO}_{2}$. The inability to program the composition of the mobile phase in CCSFC to increase or decrease solubility of the target substances in the analyzed sample was compensated by using a broad range of variations of pressure. The chromatography could be performed in the subcritical range as described by Ibanez et al. with coated, packed capillary columns [16] [17]. However, SFC in the supercritical range is more usual.

Short analysis times and low temperatures for chromatography (usually $25^{\circ}-30^{\circ} \mathrm{C}$ ) gave advantages in comparison with normal GC in analyzing thermally labile substances in mixtures. By using the CCSFC, it was possible to extend the range of molecular weights of analyzed substances in comparison with GC. In addition, the $\mathrm{CO}_{2}$ contaminated the MS not much more than the gas from the GC. The quenching of ion production in the process of CCSFC-MS was not much higher than that in GC-MS. Some signs of chemical ionization phenomena could be observed in the mass ions, additive ions and fragmentation patterns; however, this occurred to a lesser extent than in PCSFC-MS and HPLC-MS. Until recently, the disadvantages of CCSFC-MS constructions and process were more important for analysts than the advantages, and CCSFC-MS based on the GC concept saw only limited use. The use of Flame Ionization Detectors (FIDs) with CCSFC is problematic; however, several promising developments have been presented. Morrissey and Hill in [18] described metal-selective flame ionization detection in connection with CCSFC. Their conclusion was: "Using optimal conditions for achieving metal-sensitive flame ionization responses which have been established for the detector after capillary gas chromatography, initial evaluation of the detector after SFC proved promising." However, what were the "optimal conditions"? It appeared, following the authors [18]: "Like the carbon sensitive FID, it appears that the metal sensitive FID is compatible with SFC when pure carbon dioxide is used as the mobile phase. Response characteristics were found to be similar to those observed when the detector is used in gas chromatography." Generally, the use of pure carbon dioxide without modifiers or additives is necessary for the successful operation of CCSFC-FID.

\subsection{Packed Column Supercritical Fluid Chromatography (PCSFC)}

PCSFC was developed in parallel with CCSFC; however, its construction was based on HPLC concepts. Although CCSFC gained ground in the beginning because the GC concept was easier to adapt to SFs, many additional construction problems hampered the adaptation of HPLC to SFs. However, the development of Supercritical Fluid Chromatographs based on HPLC construction has progressed and achieved good results. PCSFC-MS, PCSFC-other detectors or even PCSFC-multi-detection system including MS as a detector [19] [20] are frequently seen in laboratories.

What is making this construction more preferable than CCSFC despite more technical problems? In PCSFC, binary pumps are used to deliver the mobile phase, or in addition to the binary pumps, a server pump is attached. This architecture allows the composition of the mobile phase over broad ranges of concentrations of modifier and additives to be programmed [21]-[27]. As in the CCSFC, pressure programming is also available. Backpressure regulators stabilize pressure during analyses, and compensation and programming of pressure is also available. Temperatures can also be programmed to some extent by using the column oven. Substances that are volatile or nonvolatile, thermally stable or thermally labile, stable to $\mathrm{pH}$ extremes or sensitive to hydrolyzing by $\mathrm{pH}$ can all be analyzed using PCSFC-MS. High molecular-weight compounds and even some polymers have been analyzed by PCSFC-MS [28].

The broad range of packed columns used in HPLC could be transferred to SFC [29] [30], in addition to the restricted number of columns manufactured especially for SFC [26].

Most of the detectors used for HPLC theoretically can be used for PCSFC because of the invention of highpressure optical cells and adaptation of detectors [19] [20]. Series of detectors, such as mass spectrometer, visible and ultraviolet light detector, and corona-charged aerosol detector, have been connected to PCSFCs to resolve complex analytical tasks in toxicology, biology and pharmacy [19] [20] [26].

A comprehensive review [31] of state-of-the-art PCSFC-MS at the end of the $20^{\text {th }}$ century was presented by T. R. Baker and J. D. Pinkston in their paper "Development and Application of Packed-Column Supercritical Fluid 
Chromatography/Pneumatically Assisted Electrospray Mass Spectrometry.” Leif Nyholm et al. published a report in 1999 [32] in which they stated: "A recently developed microelectrochemical detector for packed capillary column supercritical fluid chromatography $(p c S F C)$ has been applied to determine nanogram amounts of tocopherols and vitamin A in vegetable oil samples.” The use of microelectrochemical detectors with PCSFC significantly improved the ability of PCSFC, as did the introduction of the corona-charged aerosol detector [19] [20] [26]. Experiments with connection of PCSFC to a light-scattering detector (LSD) were presented by P. Carraud et al. [33] in their paper "Supercritical Fluid Chromatography/Light-Scattering Detector: A Promising Coupling for Polar Compounds Analysis with Packed Column.” In this paper, they concluded: "Detection limit is five times higher than with HPLC. With packed columns, LSD is complementary to the flame ionization detector (FID)." The use of fluorescence detection in PCSFC analyses was described in [34]. In practice, the PCSFC can be adapted to all detectors used for HPLC and to some GC detectors. With the introduction of microcolumns for HPLC and adaptation of these columns to PCSFC, it was possible to connect a PCSFC enhanced with a microcolumn to nearly every GC detector directly or by using minor modifications.

Traditionally and practically, HPLC columns were used in PCSFC. The size of columns was different, beginning from preparative and semipreparative through analytical to mini- and microcolumns. HPLC microcolumns adapted well to PCSFC, because they were designed for high and ultrahigh pressures and the connections are well constructed.

Chiral resolution by PCSFC has advantages over GC and HPLC. S. H. Hoke et al. [35] wrote in their paper "Comparison of packed-column supercritical fluid chromatography-tandem mass spectrometry with liquid chromatography - tandem mass spectrometry for bioanalytical determination of (R)- and (S)-ketoprofen in human plasma following automated 96-well solid-phase extraction” by describing the results of their experiments as: "Generally, most analytical attributes, including specificity, linearity, sensitivity, accuracy, precision, and ruggedness, for both of these methods were comparable with the exception that the pcSFC separation provided a roughly 3-fold reduction in analysis time. A 2.3-min pcSFC separation and a 6.5-min LC separation provided equivalent, near-baseline-resolved peaks, demonstrating a significant time savings for analysis of large batch pharmacokinetic samples using pcSFC." We agree with these conclusions; however, Hoke et al. omitted one very important parameter that could not be included in the experiments described. The parameter is the separation of substances in complex mixtures of different isomers with enantiomers.

Chiral columns used in HPLC and PCSFC are excellent tools for resolution of mixtures of enantiomers. Resolution of simple mixtures of enantiomers can be achieved to the baseline by both HPLC and PCSFC. The difference is only in the time required. However, this is true only for simple mixtures of enantiomers. For more complex mixtures that contain substances with close $R_{\mathrm{t}}$ and similar but not identical molecular structures (isomers), the individual isomers in the mixtures could not be resolved or separated from the enantiomers to the base line. An example of this is the poor resolution of enantiomers of primaquine from their isomer quinocide on commercial columns. We have not received permission from Supelco (see answer from R \& D Manager SigmaAldrich D. Bell, Figure 1) to use comparison of the products from Supelco and Jupiter Ltd ever in common publication.

\section{Chromatography Methodologies}

There are several basic approaches to chromatography, including thin layer chromatography TLC and column liquid chromatography, which is often called liquid chromatography (LC). The abbreviation LC is often used inaccurately, because TLC and Planar Paper Chromatography (PPC) utilize the same techniques and phenomena as "LC". Differences between LC, TLC, and PPC are in the use of thin layers in TLC and PPC, but columns in LC; however, in the literature, the abbreviations LC and LC-MS are reserved only for column liquid chromatography (CLC). Because of this, we will abbreviate this technique as CLC. Other methodologies are HPLC, capillary electro chromatography (CEC), different modifications of gas chromatography (GC), and some exotic modifications of previously named techniques.

It is of interest to compare these techniques with SFC and a relation to these by different segments of scientific and practical users.

\subsection{Attitudes of Scientists and Practical Users toward TLC, CLC, GC and SFC}

TLC belongs to a family of Planar Chromatography (PC) or Open-Bed Chromatography (OBC) [11]. The family 


\section{Yi. \\ 22 Oct \\ Dave Bell \\ to me}

The author:

"We are in Jupiter Ltd. can test some of Supelco-Aldrich Inc. GC columns on our new products, in did we doing well with the existing on the market columns, however in case of the test we are willing to publish the results in The Reporter and in J. Chromatography A, of cause in common authorship."

The R\&D Manager Sigma-Aldrich, David S. Bell:

"Basically any of our products that fit into your research can be part of the agreement. Where short articles can be extracted from the larger efforts, sure, Reporter articles can be a good means of dissemination.”

The author:

"We are interested in GC chiral columns for testing. As you know we have excellent columns for resolution of enantiomers, I am interested to publish the comparison of our column with the LC columns of Supelco-Aldrich Inc. used for primaquine. Supelco-Aldrich Inc. had published four application notes about the subject, if your corporation will give me permission to use these notes, I can in company with you publish the note in The Reporter and the paper in J. Chromatography A or other journal."

The R\&D Manager Sigma-Aldrich, David S. Bell:

"This may be more competition than cooperation.

Regards,

Dave"

Figure 1. It is a part of an e-mail from David Scott Bell, R\&D Manager Sigma-Aldrich. The blue text is from the author Dr. Ilia Brondz; the red text is from the R\&D Manager Sigma-Aldrich, David S. Bell.

of OBC includes many different modifications, including paper chromatography, thin-layer chromatography, high-performance thin-layer chromatography (HPTLC), overpressure thin-layer chromatography (OPTLC), forced-flow thin-layer chromatography (FFTLC), ascending paper chromatography (APC), descending paper chromatography (DPC), ascending-descending paper chromatography (ADPC), radial paper chromatography (RPC), two-dimensional paper chromatography (TDPC), two-dimensional thin-layer chromatography (TDTLC) and many other modifications.

OBC techniques are cheap and available in poorer countries. They are powerful tools in the hands of skilled analysts; however, results can be easily misinterpreted by ignorant scientists, as shown in [36]. TLC can even be used for the resolution of enantiomers; however, the resolution should be performed on a chiral stationary phase or using a mobile phase containing chiral selectors [36].

TLC was introduced by E. Stahl [37] about 60 years ago and is still in use. The variant of OBC known as APC was used to analyze antimalarial drugs in 1963 [38] and TLC appears in all Pharmacopeias despite its relative weaknesses in comparison with SFCs.

HPLC has many modifications, primarily based on the flow rate: open tubular LC $<25 \mathrm{~nL} / \mathrm{min}$; nano-HPLC 24 - 4000 nL/min; capillary HPLC 0.4 - $200 \mu \mathrm{L} / \mathrm{min}$; micro-HPLC 50 - $1000 \mu \mathrm{L} / \mathrm{min}$; normal HPLC 1.0 - 10 $\mathrm{mL} / \mathrm{min}$; and preparative HPLC $>20 \mathrm{~mL} / \mathrm{min}$. A broad range of stationary phases is used in HPLC. HPLC is widely used in most analytical, research, industrial and other laboratories and industrial processes. The British Pharmacopoeia in 1988 [39] offered an HPLC analysis for the antimalarial drug primaquine, which replaced the TLC analyses used before. All Pharmacopeias now use HPLC in standard procedures, but ignore SFC. It was shown that SFC is preferable to HPLC [39]-[43] both to save time and money and as a technique with less quenching of ion-production by mass-spectrometric detection. The comparison of analyses of primaquine using the same column in Figure 2 shows that more than 10 min is required for HPLC analysis. Figure 3, however, shows that SFC requires less than $5 \mathrm{~min}$. The separation of peaks is also better on the SFC chromatogram. Why is the superior technique neglected by Pharmacopeias? The comparison of HPLC with SFC analysis was presented at the meeting in Stockholm in 2005 [44].

The comparison of analysis performed by old technology of industrial columns with new technology of specialized SFC columns of an industrial sample of mixtures of enantiomers with isomers in Figure 4 and [11] shows the obvious superiority of new technology of specialized SFC columns.

GC is mainly used for analytical purposes; the use of GC for preparative fractionation is very rare, but possible. The use of normal-size packed columns is very rare at present. Normally, to facilitate GC separation, packed capillary, support-coated open tubular capillary, porous-layer open tubular capillary, and wall-coated open tubular capillary columns are used. 


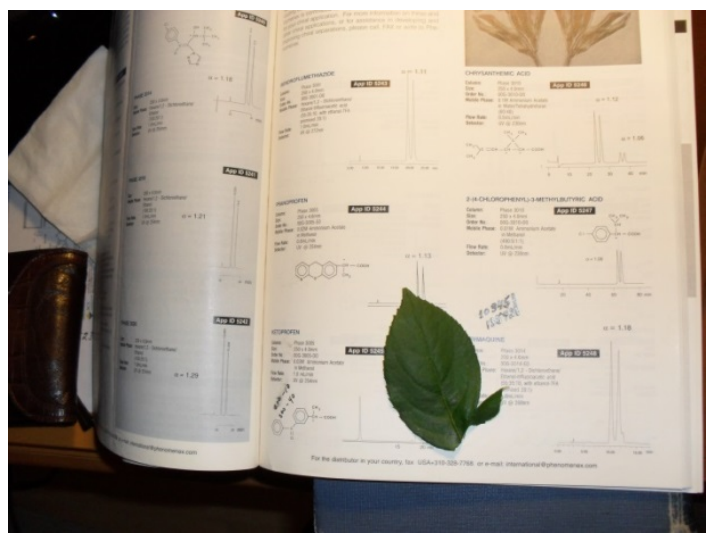

(a)

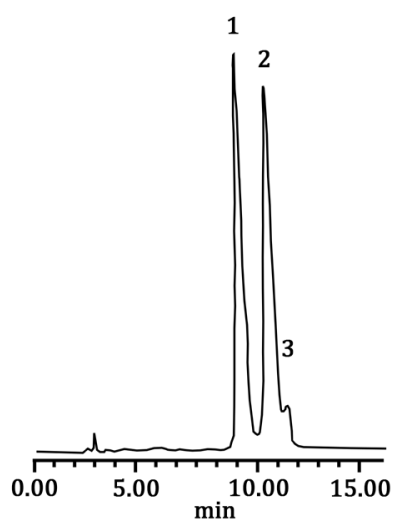

(b)

Figure 2. HPLC analysis of a primaquine standard. (a) To the left is a photograph of page 73 from the 01/02 international catalog of Phenomenex ${ }^{\circledR}$. This representative application note shows the resolution of enantiomers of primaquine and separation of isomer quinocide in a standard sample of high purity. (b) To the right is drawing from the chromatogram published in this catalog. Peaks 1 and 2 are the enantiomers of primaquine; peak 3 is quinocide, which is a constitutional isomer to primaquine.

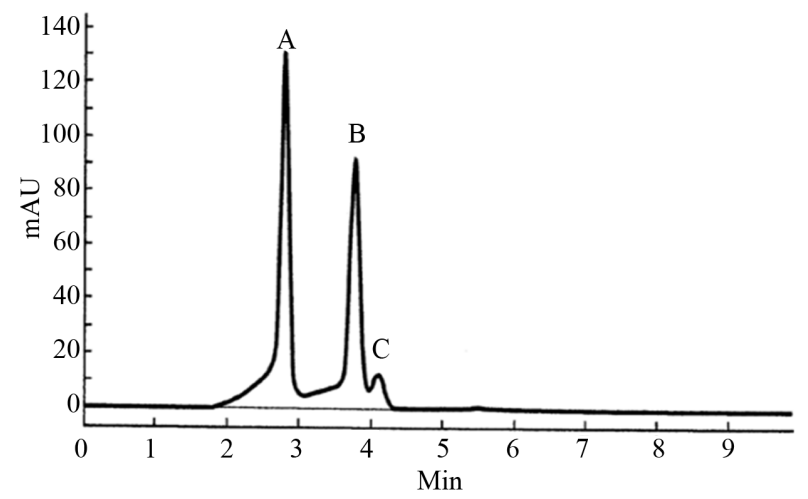

Figure 3. It shows the resolution of enantiomers of primaquine and separation of isomer quinocide in a real primaquine standard of high purity. The resolution was performed by using SFC enhanced with the column announced in the Supelco catalog (see Figure 2). The identity of the peaks was controlled by MS [21] [22].

Elevated temperature is one of the most essential requirements for GC analyses; only volatile substances can be analyzed by GC. Thermally stable substances and substances with critical thermal parameters can be analyzed by GC [45]. Thermally labile substances or mixtures containing such substances or non-volatile substances are difficult or impossible to analyze by GC. The same is true for GC-MS. Many of the problems connected with these phenomena can be overcome by the use of GC-MS with supersonic molecular beams [46]. However, this technique is still in the experimental stage: existing instrumentation is not stable and requires continual tuning by well-trained specialists, is not in serial production, and is quite expensive in comparison with classical instrumentation. The thermal stability of the substances analyzed plays a significant role in the possibility of analyzing thermally labile substances by GC, but the chemistry of the stationary phases in columns is also significant. The introduction in the beginning of the 1980s of capillary fused silica columns allowed analyses without derivatization and without pyrolysis of saturated $n$-1-alcohols and free fatty acids from $\mathrm{C}_{6: 0}$ to $\mathrm{C}_{18: 0}$ [47] [48]. The gradual development in this direction allowed improved analysis of long $n$-1-alcohols in 1983 [47]. Also in 1983, mixtures of fatty acids were successfully analyzed without derivatization [48]. Progress in column technology continues and is important because both HPLC and GC columns are used for SFC. SFC uti- 


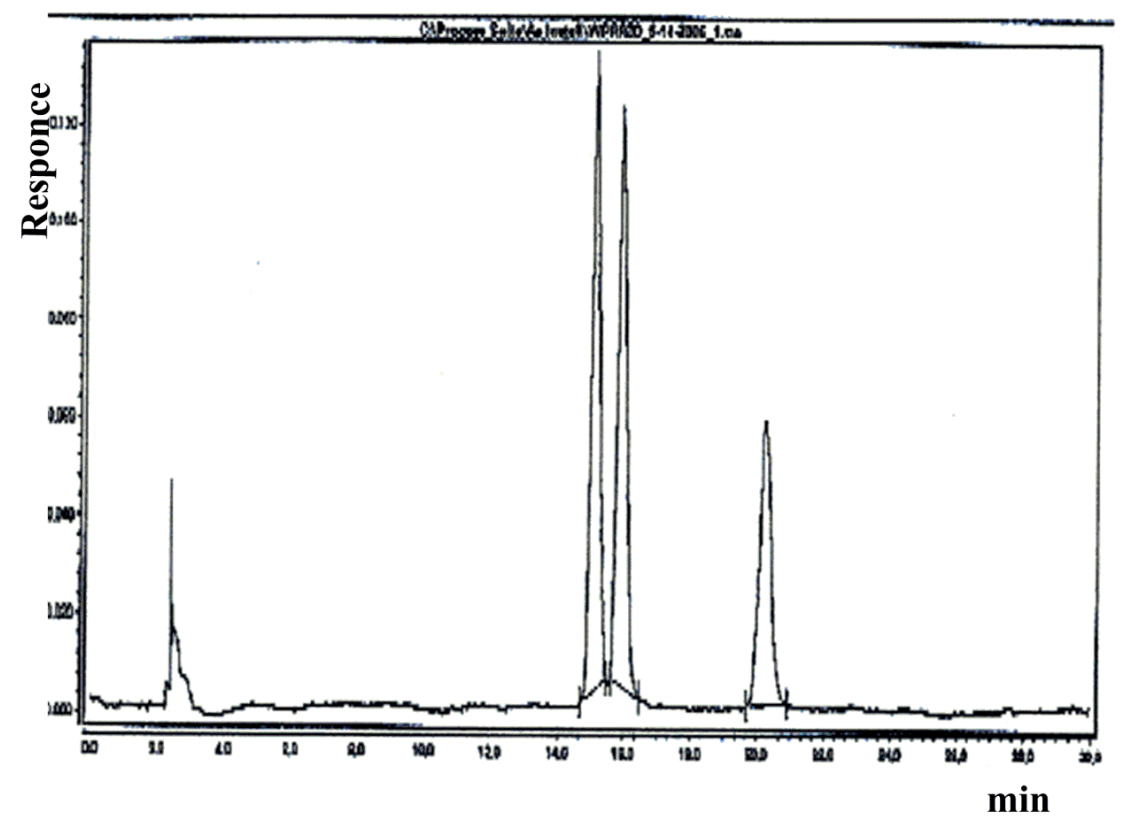

\begin{abstract}
Figure 4. It shows the resolution of enantiomers of primaquine and separation of isomer quinocide in a real sample. The sample is of raw ware primaquine as used in the pharmaceutical industry. The resolution was performed by using SFC enhanced with an experimental column manufactured by Jupiter Ltd. In this case, detection was by a corona-Charged Aerosol Detector (CAD). The identity of peaks was controlled by MS and Diode Array Detector (DAD) the multidetection approach described in [19] [20].
\end{abstract}

lizes the broad spectrum of GC and HPLC columns. The utilization of GC and HPLC instrumentation as a basis for SFC construction has allowed commercially defensible argumentation for the use of GC and HPLC columns for SFC. Is that the correct way? Only a small number of special SFC columns are on the market. Current SFC instrumentation is not unique and does not exploit all possibilities of supercritical fluids. The "Old guard" in chromatography has hindered the development of SFC and pioneering ideas are not welcome in this environment.

\title{
2.2. The Future of SFC
}

The question is: Should the use of SFs have some priority over liquids and gases in chromatography? The answer is obvious: Yes, from both practical and theoretical viewpoints [44] [49]! The diagram in Figure 5 shows clearly that with SFs, chromatographs can be operated in modes as HPLC, SFC and GC.

An important factor in increasing the solubility of organic and inorganic substances is elevation of the pressure of SFs. This can be achieved also by elevating the temperature [49], which itself increases the solubility of most substances. However, both factors can be used simultaneously. These two factors are not exploited significantly in the application practices of SFC or in the construction of SFCs.

Thermoregulation in instrumentation of SFCs is not sufficient, especially it is in detector construction. The present detectors for SFC have good pressure enforcement of optical cells, but poor thermal regulation. All concepts of detection for SFC should be changed from optical detectors to the open-ended detectors such as the corona-charged aerosol detectors described in [19] [20]. At present, pumps cannot deliver both high pressure and high volume. The construction of new pumps with ultrahigh pressure and high flow volumes should be developed. Today, most SFC columns are GC or HPLC columns. Only a limited number of columns have been designed especially for SFC [11] [19] [22] [24]-[26] [44]. The specificity of SFC and connected to this possibilities to design specialized chiral columns for separation of enantiomers from isomers with high separation power should allow the successful base line separation of isomers from enantiomers and simultaneous resolution of enantiomers in one run as shown in Figure 4 and described in [11] [19] [22] [24]-[26] [44]. Isomerism, chirality and resolution of enantiomers described in details in. New materials technologies for column support materials and stationary phases should also be developed. 


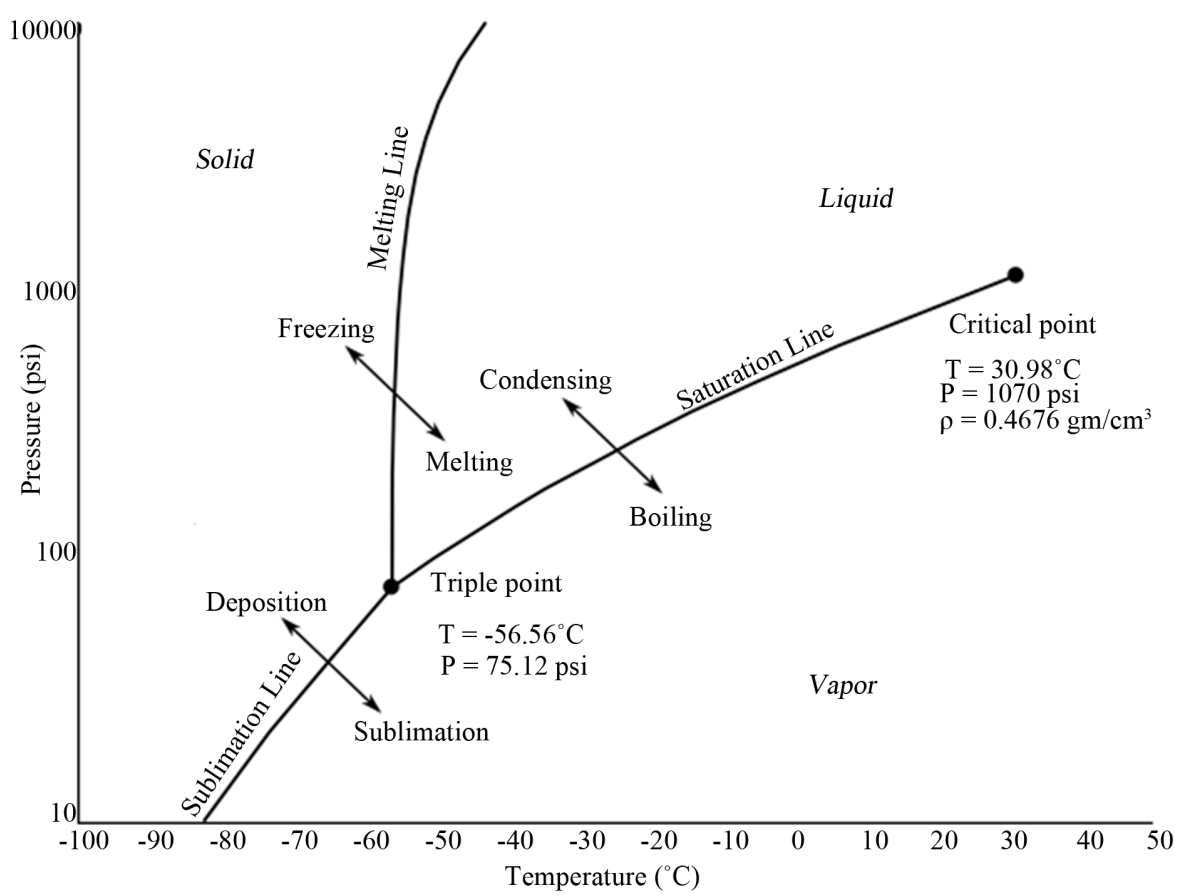

Figure 5. Pressure-Temperature relations (PSI/Celsius ${ }^{\circ} \mathrm{C}$ ) in pure $\mathrm{CO}_{2}$.

\subsection{Summa Summarum}

The four directions pointed out in Section 2.2 are: 1) new detectors, 2) improved thermal regulation, 3) new pumps, and 4) new columns. Developments of these should allow successful development of SFC. The old thinking connecting SFC instrumentation and SFC theory should be abandoned. The time has come for SFC instrumentation to be developed specifically for SFC, in contrast to the days of adaptation of GC and HPLC instrumentation. The "Old guard" of scientists and engineers who tried to adopt the concepts and instrumentation of GC and HPLC to SFC must stand aside to allow progress in developing this long stagnant area of separation analysis.

\section{References}

[1] de Latour, C.C. (1822) Exposé de Quelques Résultats Obtenupar L’action Combinée de la Chaleur et de la Compression Sur Certains Liquides, Tels Que L’eau, L’alcool, L’ether Sulfurique et L'essence de Pétrole Rectifiée. Annales de Chimieet de Physique, 21, 127-132.

[2] de Latour, C.C. (1822) Exposé de Quelques Résultats Obtenupar L’action Combinée de la Chaleur et de la Compression Sur Certains Liquides, Tels Que L'eau, L’alcool, L’ether Sulfurique et L'essence de Pétrole Rectifiée. Annales de Chimieet de Physique, 21, 178-182.

[3] Tswett, M.S. (1903) On a New Category of Adsorption Phenomena and Their Application to Biochemical Analysis. Tr. Varshavskogo obschestva estestvoispytatelei, Otd. Biolol., 14, 1-20 (in Russian).

[4] Tswett, M.S. (1906) Physikalisch-chemische Studienüber das Chlorophyll. Die Adsorbtionen. Ber.Dtsch. Bot. Ges., 24, 316-323.

[5] Day, D.T. (1897) Proceedings of the American Philosophical Society, 36, 112-115.

[6] Day, D.T. (1900) Proceedings of the 1st International Petroleum Congress, Paris, 16-28 August 1900.

[7] Kutscher, F. and Steudel, H. (1903) Beschreibung eines Ätherextraktionsapparates. Mit drei Abbildungen. Zeitschrift fur Physiologische Chemie, 39, 473-474.

[8] Schønbein, F. (1861) Übereinigedurch Haarröhrchenanziehung des Papiershervorgebrachte Trennungswirkungen. Ann Physik u Chemie 2 F (Poggendorffs Ann), 114, 275-280.

[9] The Bible, Old Testament, Exodus, 15: 25.

[10] Brondz, I. (2002) Review, Development of Fatty Acid Analysis by High-Performance Liquid Chromatography, Gas 
Chromatography, and Related Techniques. Analytica Chimica Acta, 21658, 1-37.

[11] Brondz, I. (2011) In: Brondz, I., Ed., Historical Overview of Chromatography and Related Techniques in Analysis of Antimalarial Drug Primaquine, Nova Science Publishers, Inc., New York.

[12] Audi, G. (2006) The History of Nuclidicmasses and of Their Evaluation. International Journal of Mass Spectrometry, 251, 85-94.

[13] Keithley, J.F. (1999) The Story of Electrical and Magnetic Measurements: From 500 BC to the 1940s. John Wiley and Sons, Hoboken, 205.

[14] Lovelock, J. (1973) Private Communication. W. Bertsch Thesis, University of Houston, Houston.

[15] Klesper, E., Corwin, A.H. and Turner, D.A. (1962) High Pressure Gas Chromatography above Critical Temperatures. The Journal of Organic Chemistry, 27, 700-701.

[16] Ibanez, E., Lopez-Sebastian, S., Tabera, J. and Reglero, G. (1998) Separation of Carotenoids by Subcritical Fluid Chromatography with Coated, Packed Capillary Columns and Neat Carbon Dioxide. Journal of Chromatography A, 823, 313-319.

[17] Alkio, M. (2008) Purification of Pharmaceuticals and Nutraceutical Compounds by Sub- and Supercritical Chromatography and Extraction. Academic Dissertation, Faculty of Pharmacy, University of Helsinki, Helsinki. http://www.vtt.fi/publications/index.jsp

[18] Morrissey, M.A. and Hill Jr., H.H. (1988) Metal Selective Flame Ionization Detection after Supercritical Fluid Chromatography. Journal of High Resolution Chromatography, 11, 375-379.

[19] Brondz, I., Høiland, K. and Lefler, J. (2007) Supercritical Fluid Chromatography of Secondary Metabolites and Multi-Analysis by Mass Spectrometry-Ultraviolet and Corona Charged Aerosol Detection. 12 Norwegian MS-Winter Meeting, Hafjell, 21-24 January 2007, 63.

[20] Brondz, I. and Høiland, K. (2008) Chemotaxonomic Differentiation between Cortinarius infractus and Cortinarius subtortus by Supercritical Fluid Chromatography Connected to a Multi-Detection System. Trends in Chromatography, 4, 79-87.

[21] Brondz, I., Ekeberg, D., Bell, D.S., Hustad, J.A., Svendsen, R., Vlachos, V., Oakley, P., Langley, G.J., Mohini, T., Amaury, C.G. and Mikhalitsyn, F. (2007) Nature of the Main Contaminant in the Drug Primaquine Diphosphate: SFC and SFC-MS Methods of Analysis. Journal of Pharmaceutical and Biomedical Analysis, 43, 937-944. http://dx.doi.org/10.1016/j.jpba.2006.09.017

[22] Brondz, I., Ekeberg, D., Annino, A.R. and Palcic, T. (2007) SFC-MS Analyses of Anti-Malaria Drug Primaquine Diphosphate. Comparison of Techniques and Instrumentation. Proceeding of 12 Norwegian MS-Winter Meeting, Hafjell, 21-24 January 2007, abstr. 42.

[23] Brondz, I. (2009) Chapter 5, SFC-MS Analysis of Contaminants in Primaquine Diphosphate Tablets and Spectral UV and NMR Characterizing of Primaquine and Quinocide. In: Csizmadia, E. and Kalnoky, I., Eds., Antimalarial Drugs: Costs, Safety and Efficacy, Nova Science Publishers, Inc., Hauppauge, 105-124.

[24] Brondz, I. (2009) Improved Separation of Quinocide in Primaquine Analysis by Supercritical Fluid ChromatographyMass Spectrometry. 5th Conference Nordic Separation Science Society, Tallinn, 26-29 August 2009, abstr. PP06.

[25] Brondz, I. (2009) SFC-MS Analysis of Contaminants in Primaquine Diphosphate Tablets and Spectral UV and NMR Characterizing of Primaquine and Quinocide. 5th Conference Nordic Separation Science Society, Tallinn, 26-29 August 2009, abstr. PP07.

[26] Brondz, I. and Brondz, A. (2012) The Technology for Preparation of Generic (Monoenantiomeric) Antimalarial Drug Primaquine by Using Supercritical Fluid Chromatography. Separation of Primaquine from Quinocide: Simultaneous Resolution of the Enantiomers of Primaquine and Their Separation from Quinocide in One Run. American Journal of Analytical Chemistry, 3, 884-890. http://dx.doi.org/10.4236/ajac.2012.312A117

[27] Brondz, I. and Brondz, A. (2012) Supercritical Fluid Chromatography-Mass Spectrometry (SFC-MS) of Heterocyclic Compounds with Trivalent and Pentavalent Nitrogen in Cough Relief Medical Forms Tuxi and Cosylan. American Journal of Analytical Chemistry, 3, 870-876. http://dx.doi.org/10.4236/ajac.2012.312A115

[28] Brondz, I. (2007) In: Csizmadia, E. and Kalnoky, I., Eds., Antimalarial Drugs: Costs, Safety and Efficiency Chapter V, SFC-MS Analysis of Contaminants in Primaquine Diphosphate Tablets and Spectral UV and NMR Characterising of Primaquine and Quinocide, Nova Science Publishers, Inc., New York, 105, 124.

[29] Brondz, I. and Klein, U. (2005) Separation of the Positional Isomer Quinocide from the Anti-Malarial Drug Primaquine Using a Discovery ${ }^{\circledR}$ HS F5 HPLC Column. The Reporter, 23, 1.

[30] Brondz, I., Høiland, K., Bell, D.S. and Annino, A. (2006) Indole Alkaloid Separation Using the Discovery ${ }^{\circledR}$ HS F5, Chemotaxonomic Study of Two Closely Related Brown-Spored Mushrooms. The Reporter, 23, 5-6.

[31] Baker, T.R. and Pinkston, J.D. (1998) Development and Application of Packed-Column Supercritical Fluid Chromatography/Pneumatically Assisted Electrospray Mass Spectrometry. Journal of the American Society for Mass Spectrometry, 


\section{9, 498-509. http://dx.doi.org/10.1016/S1044-0305(98)00006-3}

[32] Señoráns, F.J., Markides, K.E. and Nyholm, L. (1999) Determination of Tocopherols and Vitamin A in Vegetable Oils Using Packed Capillary Column Supercritical Fluid Chromatography with Electrochemical Detection. Journal of Microcolumn Separations, 11, 385-391.

[33] Carraud, P., Thiebaut, D., Caude, M., Rosset, R., Lafosse, M. and Dreux, M. (1987) Supercritical Fluid Chromatography/Light-Scattering Detector: A Promising Coupling for Polar Compounds Analysis with Packed Column. Journal of Chromatographic Science, 25, 395-398. http://dx.doi.org/10.1093/chromsci/25.9.395

[34] Smitha, R.M., Chienthavorna, O., Danksa, N. and Wilsonb, I.D. (1998) Fluorescence Detection in Packed-Column Supercritical Fluid Chromatographic Separations. Journal of Chromatography A, 798, 203-206. http://dx.doi.org/10.1016/S0021-9673(97)01240-5

[35] Hoke II, S.H., Pinkston, J.D., Bailey, R.E., Tanguay, S.L. and Eichhold, T.H. (2000) Comparison of Packed-Column Supercritical Fluid Chromatography-Tandem Mass Spectrometry with Liquid Chromatography-Tandem Mass Spectrometry for Bioanalytical Determination of $(R)$ - and $(S)$-Ketoprofen in Human Plasma Following Automated 96-Well solid-Phase Extraction. Analytical Chemistry, 72, 4235-4241. http://dx.doi.org/10.1021/ac000068x

[36] Brondz, I. (2013) Editorial: Analytical Methods in the Quality Control of Scientific Publications Part II: The Authors', Reviewers', Editors' Responsibility, and the Publishers' Authority. International Journal of Analytical Mass Spectrometry and Chromatography, 1, 81-89. http://dx.doi.org/10.4236/ijamsc.2013.12010

[37] Stahl, E. (1956) Dünnschicht-Chromatographie; Metthode, Einflussfaktoren und einige Anwendungsbeispiele. Pharmazie, 11, 633-637.

[38] Mshvidobadze, A.E., Chumburidze, B.I. and Sardzhveladze, O.V. (1963) Luminescent Chromatographic Analysis of Synthetic Antimalarial Preparations. Aptechnoe Delo, 12, 36-39.

[39] Brondz, I., Ekeberg, D., Bell, D.S., Hustad, J.A., Svendsen, R., Vlachos, V., Oakley, P., Langley, G.J., Mohini, T., Amaury, C.G. and Mikhalitsyn, F. (2007) Nature of the Main Contaminant in the Drug Primaquine Diphosphate: SFC and SFC-MS Methods of Analysis. Journal of Pharmaceutical and Biomedical Analysis, 43, 937-944. http://dx.doi.org/10.1016/j.jpba.2006.09.017

[40] Brondz, I., Mantzilas, D., Klein, U., Ekeberg, D., Hvattum, E., Lebedeva, M.N., Mikhailitsyn, F.S., Souleimanov, G.D. and Røe, J. (2004) Nature of the Main Contaminant in the Anti-Malaria Drug Primaquine Diphosphate: A Qualitative Isomer Analysis. Chromatography B: Biomedical Sciences and Applications, 800, 211-223.

[41] Brondz, I., Ekeberg, D., Karaliova, L., Jennings, I., Hustad, J.A. and Svendsen, R. (2005) Separation of the Positional Isomer Quinocide from the Anti-Malaria Drug Primaquine Using a Discovery® HS-F5 HPLC Column. Trends in Chromatography, 1, 78-81.

[42] Brondz, I. and Klein, U. (2006) Separation of the Positional Isomer Quinocide from the Anti-Malarial Drug Primaquine Using a Discovery® HS F5 HPLC Column. Reporter, 19, 3.

[43] Brondz, I. (2010) In: Quintin, T.J., Ed., Chromatography: Types, Techniques and Methods, Chapter 6, Historical Overview of Chromatography and Related Techniques in Analysis of Antimalarial Drug Primaquine, Nova Science Publishers, Inc., New York, 281-322.

[44] Brondz, I., Klein, U., Karaliova, L., Vlachos, V., Oakley, P., Leideborg, R. and Mikhalitsyn, F. (2005) Nature of the Main Contaminant in the Drug Primaquine Diphosphate: Comparison of HPLC and SFC Methods. 29th International Symposium on High Performance Liquid Phase Separations and Related Techniques, Stockholm, 26-30 June 2005, abstr. P12:43.

[45] Brondz, I., Klein, U., Ekeberg, D., Mantzilas, D., Hvattum, E., Schultz, H. and Mikhailitsyn, F.S. (2005) Nature of the Main Contaminant in the Anti-Malaria Drug Primaquine Diphosphate: GC-MS Analysis. Asian Journal of Chemistry, 17, 1678-1688.

[46] Brondz, I., Fialkov, A.B. and Amirav, A. (2009) Analysis of Quinocide in Unprocessed Primaquine Diphosphate and Primaquine Diphosphate Tablets Using Gas Chromatography-Mass Spectrometry with Supersonic Molecular Beams. Journal of Chromatography A, 1216, 824-829. http://dx.doi.org/10.1016/j.chroma.2008.11.043

[47] Brondz, I., Greibrokk, T. and Aasen, A.J. (1983) n-1-Alkohols of Hypericum perforatum. Journal of Natural Products, 46, 940-941. http://dx.doi.org/10.1021/np50030a025

[48] Brondz, I., Olsen, I. and Greibrokk, T. (1983) Direct Analysis of Free Fatty Acids in Bacteria by Gas Chromatography. Journal of Chromatography B, 274, 299-304. http://dx.doi.org/10.1016/S0378-4347(00)84433-3

[49] Sedunov, B. (2013) The Equilibrium Thermal Physics of Supercritical Fluids. International Journal of Analytical Mass Spectrometry and Chromatography, 1, 103-108. 